\title{
Pulmonale Erkrankungen beim Immunsupprimierten
}

\section{Einleitung}

Pulmonale Infektionen des immunsupprimierten Kindes stellen diagnostische und therapeutische Anforderungen an Pädiater, pädiatrische Onkologen, Pneumologen und Kinderradiologen. Die Patienten der pädiatrischen Onkologie stellen in diesem Kontext die größte Kohorte dar, gefolgt von den Patienten mit benignen Erkrankungen, die intensiv immunsuppressiv behandelt werden, zumeist Patienten mit M. Crohn ( $\triangleright$ Abb. 1, Patient mit M. Crohn und Miliartuberkulose unter Infliximab) oder Patienten mit juveniler idiopathischer Arthritis.

Patienten mit onkologischen Erkrankungen, die in der Chemotherapie-induzierten Aplasie Symptome einer pulmonalen Infektion aufweisen, werden in der Regel a priori breit antibiotisch behandelt.

Neben der üblichen Erregerdiagnostik (Abstriche, Blutkulturen, PCR, CMV- und Aspergillus-Ag) erfolgen in der Regel eine Röntgenuntersuchung des Thorax und mit niedriger Schwelle zur Indikation auch eine native CT des Thorax. Der CT kommt insbesondere in der Frühdiagnose einer Pilzinfektion eine wichtige Aufgabe zu, auch die Planung invasiver Diagnostik mittels bronchoalveolärer Lavage erfolgt anhand der CT. In Einzelfällen kann eine CTgesteuerte Lungenbiopsie die Ultima Ratio

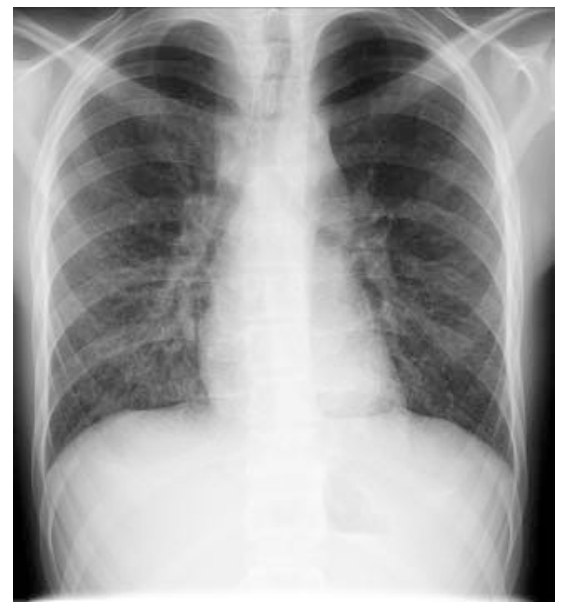

Abb. 1 Patient mit M. Crohn und Miliartuberkulose unter Infliximab.

der Diagnostik bei den schwerstkranken Patienten sein.

\section{Ziel}

Im Vortrag werden die häufigsten pulmonalen Infektionen des immunsupprimierten Kindes anhand typischer und atypischer Befunde vorgestellt; neben den bakteriellen Erregern werden insbesondere die Pilzinfektionen (Aspergillus) und virale Infektionen (CMV, RSV, Influenza- und Adenoviren) anhand richtungsweisender Befunde präsentiert.

1. Bakterielle Pneumonien sind meist durch Staphylokokken, Pneumokokken oder Hämophilus influenza verursacht, seltener durch Pseudomonas, Klebsiellen oder Proteus mirabilis. Im Rahmen einer Sepsis bei neutropener Kolitis können E. coli und andere Erreger in die Lungen streuen. Radiologisch variieren die Befunde in Abhängigkeit von der Zahl der Leukozyten: In der Phase der Aplasie sind die Patienten oft nicht in der Lage, das Vollbild einer bakteriellen Lobärpneumonie auszubilden, im frühen Stadium ist schon bei einer lobären Milchglastrübung an eine bakterielle Infektion zu denken. Die Tuberkulose ist zwar insgesamt selten, sie kann radiologisch das ganze bekannte Spektrum einer aktiven spezifischen Infektion bieten. Im Kindesalter ist häufig eine einseitige hiläre Lymphadenopathie nachweisbar.

2. Virusinfektionen der Lunge sind häufig durch CMV, RSV, Adeno- oder Influenzaviren bedingt. Radiologisch stehen interstitielle Infiltrate im Vordergrund, zudem bestehen oft fleckförmige alveoläre Infiltrate ( $\triangleright$ Abb. 2, Patient mit ALL unter Chemotherapie mit RSV-Pneumonie). Radiologisch kann nicht zwischen den viralen Erregern differenziert werden, eine beglei- 


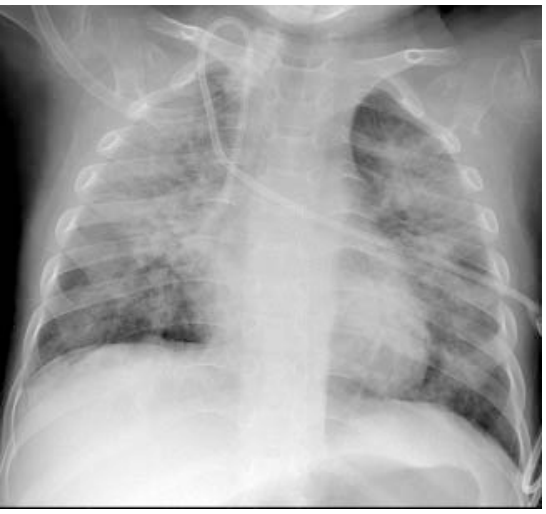

- Abb. 2 Patient mit ALL unter Chemotherapie mit RSV-Pneumonie.

tende Überblähung kann ein Hinweis auf eine RSV-Infektion sein. Koinfektionen mit mehreren Erregern kommen nicht selten vor. Eine Mykoplasmen-Pneumonie ist eine wichtige Differenzialdiagnose interstitiell dominierter Infiltrate, häufig findet sich ein geringer Begleiterguss.

3. Pilzinfektionen werden meist durch Aspergillen, seltener durch Candida oder Mucor verursacht und sind insbesondere bei Patienten nach allogener Knochenmarktransplantation zu beobachten. Klinisch bestehen ein antibiotikaresistentes Fieber, hohe Entzündungszeichen und häufig Schmerzen bei der Atmung. Radiologisch dominieren in der Frühphase noduläre Herde, aber auch ausgedehnte periphere Konsolidierungen können vorkommen. Die CT kann in der Frühphase die Pilzherde mit einem hyperdensen Halo darstellen; erst nach 14 Tagen sind die klassischen Zeichen der Einschmelzung des Pilzherdes mit „Luftsichelzeichen“ (air crescent sign) zu erkennen ( $\triangleright$ Abb. 3a, b Patient mit Asper-
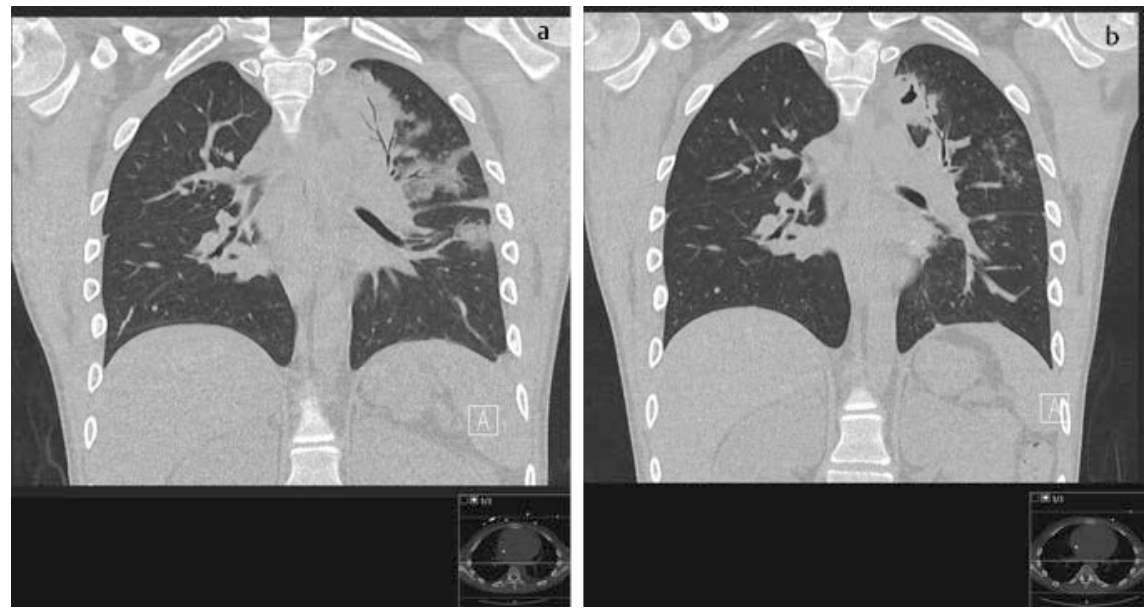

- Abb. 3 a, b Patient mit Aspergillose nach KMT, initial ausgedehnte Konsolidierung gefolgt von Einschmelzung.

gillose nach KMT, initial ausgedehnte Konsolidierung gefolgt von Einschmelzung). Pneumocystis-jiroveci-Infektionen sind durch beidseitige, symmetrische, interstitielle Infiltrate gekennzeichnet, in der CT ist eine Milchglastrübung mit scharfer Begrenzung und fokalen Aussparungen typisch.

\section{Interessenkonflikt}

Die Autoren geben an, dass kein Interessenkonflikt besteht.

\section{Autorinnen/Autoren}

Jörg Schaper

Institut für Diagnostische und Interventionelle Radiologie, Universitätsklinikum Düsseldorf
Korrespondenzadresse

Dr. med. Jörg Schaper

Kinderradiologie

Institut für Diagnostische und

Interventionelle Radiologie

Universitätsklinikum Düsseldorf

Moorenstraße 5

40225 Düsseldorf

joerg.schaper@uni-duesseldorf.de

\section{Bibliografie}

DOI https://doi.org/10.1055/a-0943-1511

Online-Publikation: 2019

Fortschr Röntgenstr 2019; 191: S125-S126

(c) Georg Thieme Verlag KG, Stuttgart · New York ISSN 1433-5972 